\title{
DEVELOPMENT OF THE MAGISTRATE'S INTIME CONVICTION IN THE CONTEXT OF NON-VERBAL COMMUNICATION
}

\author{
Marțian Iovan* \\ “Vasile Goldiş” Western University of Arad, Romania, E-mail: iovanm@uvvg.ro
}

(Received: November 2020; Accepted: January 2021; Published: May 2021)

\begin{abstract}
The author of this paper tackles the concept of intimate conviction of the magistrate (judge, prosecutor) and relevant aspects of the etiology and practical importance of its content, as a subjective basis for establishing judicial questioning tactics that help the magistrate in his/her decision-making. By approaching the process of intimate conviction development as part of an interpersonal communication system, the author analyses the contribution of interpreting nonverbal, extra-semantic clues given by the person being questioned and by all participants in courtroom debates, to the detection of feigned behaviors and the subsequent adjustment of questioning, paving the way for the development of an intimate conviction. Consequently, improving hearing and questioning practices for the accused, the investigated, and witnesses involves professional control and self-control in terms of eye contact, facial expression, gestures, stance, paralanguage, touching, proximity, and dress, in order to masterfully achieve specific goals in delivering justice.
\end{abstract}

Keywords: intimate conviction; questioning; feigned behavior; nonverbal clues; judicial decision.

\section{Introduction}

Convictions are superior components of motivation, with cognitive, affective, and valuable content, embodied in ideas that are deeply rooted in the structure of personality. An idea becomes a conviction only when an individual sees it as a value, a subjective certainty that can be justified with arguments believed to be unshakeable/uncontestable.

Convictions, according to the classification of an American psychologist (Abraham H. Maslow, 1954), are placed in the superior category of motivation and are related to spiritual, ethical, knowledgeable, or self-awareness needs. Convictions operate as force ideas, as value ideas, and are equivalent to a person's needs, professional and

\footnotetext{
${ }^{*}$ Corresponding author: Marţian Iovan.E-mail: iovanm@uvvg.ro
} reproduction in any medium, provided the original author and source are credited. 
Iovan, M., (2021)

Development of the Magistrate's Intime Conviction in the Context of Non-verbal Communication

personal ideals, worldview, and religious faith; they are actualized as motives in action, especially when the person is in the position to make certain decisions or is engaged in a conflict of values. Under such circumstances, the stronger, more unshakeable convictions shall act, to a greater extent, in orienting decisions and choices and justifying options. A conviction is constantly promoted by a person, and when it is contradicted or attacked by others, this person will go to great lengths to defend it.

The intimate conviction of an investigator or magistrate is a forced idea, value idea, correlated to good faith, which develops gradually during criminal prosecution and judicial investigation, as new direct and indirect evidence is gathered to ensure the ascertainment of truth and a correct judicial decision. In this context, we may agree to the following definition given to the intimate conviction of a magistrate/investigator (Butoi, 2004):

In law, intimate conviction is the psychological state of persons who are responsible for applying laws, based upon good faith, who are reconciled to their own moral conscience, which has guided them in ascertaining the truth, by using legal means, and in taking legal measures required by the established state of affairs.

A favorable social and institutional framework for the development/consolidation of the magistrate's intimate conviction is one in which human and civil rights are guaranteed, in which the constitutional principle of separation of powers is consistently applied, and in which the principle of magistrate independence, impartiality and integrity is respected - as magistrates shall only be subject to laws. The intimate conviction of an investigator or judge is a cognitive/value-related motivational formation, based on good faith and constituting the source of opinions, evaluations, circumscriptions, and personal options for each member of the panel during deliberation, motivating judicial decision. Deliberation carried out by the judge after the conclusion of debates is centered, first and foremost, on matters of fact (i.e. those closely related to evidence) and then on matters of law, regarding the classification of the crime and the application of the due sentence. Complete sufficiency and coherence of evidence is the objective basis for reconciling the magistrate to his/her moral conscience, for shaping an intimate conviction that the solution to the case is just and equitable.

In judicial practice, the process of developing the intimate conviction of the investigator or judge is not straightforward and uniform. Several obstacles may prevent the shaping and development of a conviction regarding juridical truth, such as the absence of direct evidence, the intelligent and creative duplicitous behaviors of certain defendants during the process of judicial investigation, the pressure of public opinion, the contrary or contradictory character of the intimate convictions of the two protagonists in a legal battle (the prosecutor and the defense lawyer) in terms

84 S sciendo Journal of Legal Studies Volume 27 Issue 41/2021 
of how the case should be solved, the prosecutor or lawyer's attempts at taking advantage of the sensibilities and weak points of magistrates, etc. If the magistrate did not develop a definitive intimate conviction, the case must be reprised or redocketed. The legislator foresaw the event of re-docketing cases in which magistrates did not succeed in developing an intimate conviction after the debates had ended, the final pleas had been delivered on both sides, and the defendant's last word had been heard - as a subjective and moral basis for reaching a legal decision. As a conclusion that may be drawn from the above-stated, we might suggest that G. F. W. Hegel (1963) - a great classic German philosopher of law -, expressed a historical truth by writing that:

the duty of deciding must fall to subjective conviction and conscience (animi sententia), and when the evidence rests on depositions and statements, the oath, though a subjective confirmation, is ultimate.

Therefore, the basis for the intimate conviction underlying the judicial solution, from a psychological perspective, is the thorough knowledge, by law enforcers, of the principles and laws governing the psychology of personality and small groups, the use of specific psychological techniques, their own morality and good faith, as marked by professional honesty (honeste vivere), rightful intention, diligence, legitimacy and abstention from producing damage to others. Intime conviction is a result of gathering and interpreting evidence, testing the truth of testimonies and statements by the parties involved, evaluating and cross-examining the various reports of participants in the criminal trial.

The management of communication occurring among participants in the judicial process, by magistrates, is an essential component of factors that may influence the development of intimate conviction. This study will now turn to the analysis of aspects influencing the development of the magistrate's intimate conviction, which are due to nonverbal communication and the magistrate's struggle with himself/herself on a subjective, psychological plane, to preserve his/her independence and integrity.

\section{Interpreting nonverbal clues, feigned behavior, and the intimate conviction}

The interpersonal relationship between the investigator and the investigated essentially presupposes communication. Practically, the act of justice is achieved through the agency of communication, which is ubiquitous in pre-and post-criminal phases, in criminal prosecution, in courtroom debate sessions, in a judicial investigation, in deliberation, in a prison environment, or the work of reeducating reinserting criminals onto the labor market. For these reasons, elements of communication psychology shall condition the transition from the science of law to the mastery and art of organizing judicial investigation, hearing witnesses, managing 
Iovan, M., (2021)

the confrontation between the two lawyers, communicating in the courtroom, etc., in the sense of increasing the efficiency and quality of the act of justice.

Communication, as the transmission of information from one person to another, has a verbal component (due to the use of language) and a nonverbal, extralinguistic one (beyond the use of words), or, in other words, it has a semantic and an extrasemantic component. In verbal (oral or written) communication, importance is attached to the choice of words, to how sentences are built, these resulting in great differences among individuals in terms of ability to verbalize, styles of verbal communication, capacity for subtle, nuanced expression. Concomitantly to verbal communication, we involuntarily and, most of the time, unconsciously use a variety of signals (termed clues), which pertain to nonverbal/extralinguistic communication. The scope of nonverbal clues is composed of expressions of eye contact between the interlocutors, facial expressions, gestures, poise, paralanguage, touching, proximity, dress, body contact, head movements, the person's physical appearance, the odor emitted by the communicator.

Nonverbal communication codes are limited to face-to-face communication, having two functions (Fiske, 1990):

The first, as we have seen, is to convey indexical information. This is information about the speaker and his or her situation through which the listener learns about her or his identity, emotions, attitudes, social position, and so on. The second function is interaction management. The codes are used to manage the sort of relationship the encoder wants with the other. By using certain gestures, posture, and tone of voice, I can attempt to dominate my fellows, be conciliatory towards them or shut myself off from them.

Nonverbal expressions are perceived, may be observed, and, to a certain extent, ascertained by the interlocutor, whether s/he is a magistrate, an investigator, a lawyer, a defendant, a victim, a witness, or an expert. Messages and information transmitted through nonverbal clues may be consistent with what is expressed in words; they may strengthen and nuance certain meanings of verbal communication. There are, however, frequent instances in the process of judicial investigation, in the wording of a witness's testimony, in the contradictoriness of the judicial trial, where inconsistencies, incongruities, oppositions occur between the two types of communication. These may appear in the case of feigned, duplicitous behaviors and lies. Yet, an investigator or magistrate endowed with flair, professional tact, and intuition may observe and interpret the deceptive nature of the expressive manifestations of the defendant's affectivity/personality, may adopt changes of tactics during the process of questioning or hearing, or new procedures in conducting an investigation, thus enhancing his/her opportunity to perform well in achieving his/her professional mission. 
In their turn, the defendant or any of the litigating parties, provided they have psychological training, experience in the field of communication, a certain amount of "practice in nonverbal communication", may certainly draw meanings from the nonverbal or paraverbal communication of the prosecutor who runs the judicial investigation, of the judge or president of the court. In some cases, the persons investigated as parties in the litigation attempted to take advantage of such manifestations of the magistrate's nonverbal conduct; as such, they changed their attitude and tactics, and they invoked evidence of infringement of the principles of impartiality and integrity on the part of those magistrates. Examples of such nonverbal manifestations are frequent in judicial communication: the investigator raising his/her voice, the use of subtle irony, the use of a deceptive question; repeated approval (as shown by the judge nodding his head) of the reports of one witness; threatening glances in communication with one of the parties; gestures and facial expressions of the investigator, implying that he is under the influence; the alternation of proximity (distance) between the parties (for example, a judge allows the prosecutor to approach and enter his private space, while the defense lawyer is required to keep the official distance); certain facial expressions and smiles with approving significations, in communication relations with a defendant who is a minister, etc.

The interpretation of such nonverbal displays by a neutral observer, by an expert psychologist, or by journalists, raises doubts as to the objectiveness, independence, impartiality, and integrity of some magistrates. Yet, in cases where the ethics and deontology of magistrates are adulterated by certain perturbing factors in communication, the magistrate's process of developing his/her intimate conviction will certainly escape the regulating control of his/her good faith. This serves to show how important it is for the magistrate to have some knowledge of communication theory and judicial psychology, in order for his/her professional activity to attain the level of professional mastery, effectiveness, efficiency, and desirability, as social expectation.

We shall rest, as follows, upon a few components of nonverbal communication in the conduct of judicial investigation and courtroom debates:

- eye contact between the interlocutors (police officer - suspect, judge - witness, the prosecutor - defendant, lawyer - expert, criminal - victim, etc.) is one of the most powerful nonverbal clues, and an indicator of emotions, interests, and intentions. The length, orientation, and type of eye contact, the object of an interlocutor's visual focus while s/he speaks have an informative value for the investigator/magistrate. Likewise, the avoidance of direct eye contact, switching one's focus from one object to another, long glances, striking gazes, the barring of eye contact may have played important parts in communication that is specific to interpersonal relations of 
Iovan, M., (2021)

opposition and confrontation. The most relevant functions of eye contact (according to Argyle - 1975) are the following:

a) it expresses emotions and other affective processes;

b) it regulates the flow of conversation;

c) it provides feedback to the speaker on what s/he has communicated,

d) it reciprocally informs participants in a dialogue on the nature of their relations.

Interpreting the clues derived from eye contact is a matter of probability. Thus, it is believed that closely watching an object or a movement is a sign of interest/attention, while eye contact would respond to the interlocutor's need for approval, the frequency of eye-blinking and eyebrow-shifting might express certain feelings, relaxed eye muscles when eyes are not wide open would express sympathy for the interlocutor, pupil dilatation would express pleasure caused by the interlocutor's presence, fixed and vacant stares would be indicative of withdrawal from reality, downcast eyes might show humility, guilt or shyness, etc. Such clues appear to the background of verbal communication and can be interpreted by any of the participants in the dialog. For this reason, eye control must be cultivated, educated, and censored by all those who work in the judiciary, to not allow themselves to be approached, ,read" and interpret by the accused, false witnesses, etc. Awareness of the meanings attached to clues resulting from eye contact and their use in the magistrate's professional dealings might have higher pragmatic valences.

A magistrate's promotion of the 'supremacy of the law' principle, of neutrality and equidistance from the parties involved in a trial, of good faith, is externalized in natural, neutral, distributive glances, according to the correct application of the procedure, which requires communication to be subordinated to it; a magistrate's eye contact with another party to the trial must not leave room for possible interpretations of partiality in favor or against that party. A neutral observer, the defendant in the case or the press might immediately start to doubt the independence and impartiality of the magistrate, if s/he avoids looking in the direction of one party and instead insistently and repeatedly gives "positive", "admiring" glances to the other party, or absently looks out the window while the lawyer of one of the parties pleads, or looks frowningly and defiantly at the defendant when his lawyer demonstrates the existence of extenuating circumstances, or admiringly focuses on the prosecutor involved in the case (who is known to be a friend of the judge's), or if the first time that he lifts his eyes from the file, since the very beginning of the trial, is when the high dignitary accused of corruption is brought before the court, etc. Such expressions of "eye-to-eye" communication may become suspicious to one of the parties in the courtroom or an independent observer, and are often taken as premises for attacks on the magistrate's professional integrity. The press or the 
hostile pressure groups know how to make use of such nonverbal expressions of the magistrate to attain their purposes.

- facial expressions can take a large number of possible forms, which carry specific messages. There are certain facial expressions that bear the same meaning everywhere in the world; in other cases, the facial expressions of affective processes (emotions, feelings, passions) are culturally determined (by habits, traditions, collective mindsets). The range of possibilities for expressing feelings, emotions, or moods through facial expressions is extremely wide. In this respect, there are wellknown, typical facial expressions for fear, anger, threat, curiosity, sadness, astonishment, surprise, happiness, contempt, pessimism, etc. Facial indicators provide feedback in the interpersonal contact taking place in a judicial investigation office or during courtroom debates, and they can reciprocally adjust the conduct of those involved in criminal prosecution / criminal trials, adapting communication according to the signals received from the sender (prosecutors, judges).

For the investigator or judge, facial expressions displayed by the accused, by a false witness, by persons that are very close to the accused, have interpretable, decodable meanings. This is even truer if the magistrate has thorough psychological knowledge and experience. Common people have natural, genuine facial expressions, while suspects and false witnesses, under the pressure of virtual punishment, shall frequently attempt to play the part of a common person, that is, to convert psychological states, emotions and other primary effects that unconditionally accompany immoral and illicit behaviors, into contrary expressions. But for this to happen, the accused has to be a very good actor. Even with a talent for acting, it is impossible for contrary signals, evidently artificial and compromising, to be muffled completely. The duplicitous attitude of the criminal may be relatively easily identified by an experienced investigator, who has benefited from sound psychological training, by analyzing the meanings of facial expressions that appear when he has to respond to questions that trigger certain emotions.

Criminals may also harness communication skills, especially as regards nonverbal communication, resulting either from the nature of their profession (in the case of physicians, sociologists, psychologists, journalists, priests, etc.) or from a thorough knowledge of this field. As such, magistrates must have, in their professional dealings, a fair amount of self-control over their conduct as interlocutors, to avoid the emergence of nonverbal communication breaches, which might then be interpreted by the investigated to their advantage, and followed by changes in their tactics. This might hinder the attainment of performance in a judicial or criminal investigation.

- poise - the position of the body, reactions in which the entire human participate, positional echo, gait, gestures, are all indicators and ways of communicating 
Iovan, M., (2021)

Development of the Magistrate's Intime Conviction in the Context of Non-verbal Communication

information that is auxiliary to what is transmitted verbally, and which may be intentional but which, most often, are unconscious, unconditioned forms of communication. The position of the body (standing, slanting, sitting, etc.) may indicate tiredness, drowsiness, hyperactivity, increased attention, empathy towards the speaker, assumption of the master role in communication, defiant attitude, etc. Poise, combined with gestures made by the participants in communication, transmits the most subtle of signals, such as attitudes of approval/disapproval, reactions of affirmation/negation, feelings of apprehension/expectation, trust/distrust, hatred/desperation, offensive/defensive attitudes, joy/sadness, etc.

Stance and gestures are dependent on the interlocutors' status. Generally, listeners (the accused, the suspect) tend to make fewer gestures than speakers; this also applies to those who hold an inferior status in the communication, with respect to those who have a superior status, or to those who have no authority, concerning those who are officially vested with authority by the state (magistrates).

Gait, in connection to gesticulation and the reaction speed of the subject who communicates and receives information, emotions, and feelings, provides clues on certain psychological particularities of the person at that moment. Speed of movement, pace changes, elasticity and ampleness of gestures, firmness of steps, alternation of forms of movement, are clues to the neuropsychological mobility, to the temperamental profile, to the person's level of energy and effective configuration. For example, a firm, fast gait, with ample and lively steps indicates a good mood, self-confidence, and optimism. On the other hand, a slow gait, with small steps, might signify a lack of energy, old age, depression, sadness. In many cases, affective shock can trigger gait dysfunctions.

- touching and proximity give relevant clues to the nature of affective relations, to the presence of attitudes, interests, feelings in those who communicate. The reflex of touching the interlocutor expresses a certain emotion or affective mood which might take the form of a greeting, a kiss on the hand, a caress, spontaneous and unconditioned touch, etc. In social gatherings, touching, as a part of communication, and also as a part of communication between the sexes, is regulated by moral norms. It may be remarked that touching might signal not only gender and age but also social status. The most frequent situation is when people with higher social status are those who initiate touching (by stretching out their hand, by amicably patting the interlocutor on the back, by wrapping their arm around the person's shoulder, etc.), while people with a lower social status allow themselves to be touched, but will not initiate acts of touching. In interpersonal relations occurring as part of a judicial investigation, in communication taking place throughout a criminal trial, touching transmits complex signals in a criminal - victim relation. A defendant's initiative of touching the prosecutor, or a police officer touched by a suspect, are rarities. Instead, settling on a range of touching techniques practicable by investigators is crucial for

90 S sciendo Journal of Legal Studies Volume 27 Issue 41/2021 
attaining the goals of questioning, for creating, in the investigation office, a sociohuman ambient that favors communication and, especially, trust. In this area, as well as in public spaces pertaining to law enforcers, touching is rationalized, stylized, subject to voluntary self-control, and targeting the accomplishment of professional goals.

In general, reciprocal touching expresses affective relations, of closeness, solidarity, friendship, the affective attraction of varying degrees. In relation to conflict, emotionally triggered touches are absent; the tendencies of persons and groups are centrifugal and tend towards separation. In the case of communication in the investigation office or the courtroom, communication is oppositional and expresses the magistrate's authority over the other interlocutors. Inasmuch as touching occurs, it is rationally and professionally regulated, and it is normally initiated by the person in authority.

Proximity, i.e. closeness allowed between the prosecutor and the defendant, between the judge and the defense lawyer, between the police officer and the witness, etc., is another form of extraverbal communication that provides information about social relations among the participants, their affective states, reciprocal attitudes, etc. According to habits and mindsets, in any society, there is an outlook on private space, which the individual strives to protect, and this includes the optimal distance between participants in a dialogue. The degree of relatedness and friendship seems to influence interpersonal distance. The more intimate, familiar, or friendly a relationship is the more distance and private space decrease. In the case of courtspecific communication, private space and proximity, albeit not legally regulated, are traditionally managed by respect induced by the prevalently institutional character of relations and by the specific authority of a state institution.

In judicial communication, several forms of expression by touching and adjusting proximity have raised questions from neutral observers, the press, or litigants, with regard to the impartiality and deontology of magistrates. Thus, for example, the judge involved in solving a case of corruption had her hand kissed by the accused within the premises of the court; the prosecutor and the defendant had a tête-à-tête during the intermission of an opera show; the judge and the defense lawyer communicate, in the courtroom, by sitting on chairs at a distance of $30-40 \mathrm{~cm}$ (while the official distance between them should be approximately 10 times longer, and the lawyer must not sit unless invited to do so by the magistrate); the young judge was caressed by an unmarried doctor, charged with bribery; the judge and the lawyer of one party to the trial had been seen, during the evening before the trial sessions, dining in an expensive restaurant; the judge and the father of the young men charged with involuntary manslaughter had been seen hunting together; the prosecutor and the defendant had been seen playing tennis on a weekly basis, etc. 
Iovan, M., (2021)

Development of the Magistrate's Intime Conviction in the Context of Non-verbal Communication

Such elements of communication come to incite public feelings of distrust in the act of justice and become subjects of tabloid reports.

- paralanguage, i.e. speech particularities that refer to verbal flow, tone, rhythm, pauses, reprisals, speech modulations, transmits the additional information to what sentences convey. Certain strong emotions - such as anger, hatred, terror, anxiety, elation, etc., are externalized in specific intonations and may cause stammering, incorrect use of language, or repetition. When the speaker is hesitant about the reaction his collocutor will have, this may result in pauses or space-fillers such as "err...”, „umm...”, „or maybe not, err, or umm, uh...". The emotional state of the communicator unconsciously leaves its mark on the actual timbre of the voice: positive emotions are reflected by a warm and resonant timbre, whereas a negative emotion, such as anger, is marked by a strident, loud timbre.

The rate of speech or verbal flow is a way of communicating information. Slow speech may be indicative of insecurity, prudence, tiredness, etc., whereas fast speech might mean that the magistrate is worried and anxious. "Precipitous" speech, pauses in verbal flow, pronunciation, fluency offer clues as to cognitive processes, temperamental profile, the dynamics of affective life, demonstrating how useful paralanguage is in inter-human communication. The importance of paralanguage for the judicial and criminal investigation and the criminal trial as a whole results from the analysis of the hypothesis that these might be conducted only on the telephone or only in writing. In such situations, no meanings could be drawn from nonverbal communication clues, with their entire wealth of virtual interpretations.

In some cases, paralanguage that occurs in the communication of magistrates may provide elements that infirm good faith or their efforts of finding sufficient evidence and support leading to the development of intimate conviction, based on the reestablishment of the truth resulting from the sufficiency of necessary evidence. Such judicial trials take place in times of social revolutions, in the case of judging political leaders, highly reputed personalities in culture, science, religion, economics, etc. (for example a high priest of the Catholic Church, charged with child abuse; the president of a world bank, charged with rape; a great director, a world champion in sports, charged with robbery or assault; a politician - senator, president of the state, minister - charged with involuntary manslaughter; a president of a state or high dignitary, charged with corruption, etc.). Trials focused on solving such cases involve communication between participants in the courtroom, among which are two authorities: the functional authority of magistrates and the informal, specific authority of a prestigious personality, accompanied by the authority of his/her official position (or a "shadow" that is left of it). The extraverbal conduct and especially the paralanguage of magistrates throughout criminal investigation and courtroom debates may undergo certain deviations from standard procedure. A good example in this respect is the trial of Nicolae Ceauşescu and other historical

92 S sciendo Journal of Legal Studies Volume 27 Issue 41/2021 
personalities of the same type (Saddam Hussein, H. Mubarak, etc.). From the perspective of the panel and the rioting crowds, that trial was legitimate, whereas the accused considered it not only illegitimate but also illegal. Such instances of communication, including paraverbal, are an example of how criminal investigations and judicial debates must not be conducted. Even though the trial was started under political pressure and on command, the magistrates and the other "judges" involved should have demonstrated, in a manner that included nonverbal and paraverbal expressions, that they were independent, impartial, integrous, and bearers of the dignity of their position. However, expressions such as: raising one's voice, timbre, trembling speech, pauses, stammering, reprisals, phrasing, alternations of speech rate, menacing facial expressions, etc. can be interpreted as signs of professional insecurity, noncompliance with standard procedures, bad faith arising from hatred, vengeance, and anxiety, caused by the presence of a historical character, deemed evil by the magistrates.

The communicator's personality is also expressed in dress, jewelry, hairstyle, tattoos, hygiene habits, physical appearance. The following text contains selfevident truths (Hayes \& Orrell, 1997):

Another way that we can communicate with one another, without the use of words, is through dress. We are all familiar with the various uniforms which are used to signal that someone is occupying a particular role in society: a policeman, nurse, or traffic warden for example. But other forms of dress may also communicate information about the person/ someone in a professional job, for instance, like a solicitor, will tend to dress neatly and in a particular kind of style, while someone who has a more physical job is unlikely to be seen wearing a suit except on very special occasions. So by "reading" the ways that people dress, we make judgments about them which gives us a rough guide on how to interact with them.

Elements of dress, such as cut, blending of colors, neatness, adherence to fashion trends, accessories, etc., provide various clues about an individual's material and professional status, about how they wish to be perceived by others, enabling one to extract from it psychological meanings that are useful to the exercise of law enforcers' professional roles.

A magistrate's status is institutionally recognized, a judge or prosecutor's profession being identified by signs, symbols, dress, color (the goddess of justice, the balance, the robe, the logo, the stamp, etc.). Standardization, to a certain extent, of a magistrate's role, has continuity up to the level of options for a dress to be worn within the premises of the institution, including hairstyle and jewelry. All these must be contained within the limits of decency, common-sense esthetics, and hygiene. In practice, some exceptions were found, such as a judge who returned to the court from 
Iovan, M., (2021)

Development of the Magistrate's Intime Conviction in the Context of Non-verbal Communication

a mystical-religious session of the so-called mission for the spirit's integration into the absolute (MISA), negligently dressed and with an unusual hairstyle; the prosecutor who came to work after a night of playing poker, shabbily dressed, reeking of cigarette smoke and wearing an earring; a judge wearing an excess of head, neck, hand and leg jewelry, exuding an intoxicating perfume odor; the negligent dress (no tie, shirt hanging partially from the trousers, dusty shoes, etc.) of an inebriated magistrate, combined with specific, inappropriate poise and gestures, etc. All these expressions of nonverbal communication may be interpreted in the sense that the main concern of the magistrate is not to accomplish a qualitative act of justice but, rather, their addiction to certain hobbies or even vices. Receiving such interpretations, the public will again question the credibility of the act of justice, the transparency of communication in the judiciary, and the fairness of some judicial decisions whose actors are persons such as those exemplified above. One must, however, emphasize the fact that, in order to optimally accomplish an act of justice, greater importance must be attached to the interpretation, by magistrates, of nonverbal expressions manifested by defendants and false witnesses, of the extraverbal conduct of parties confronting one another in a trial. The identification of duplicitous expressions and feigning is a form of talent and professional mastery in magistrates and investigators.

Consequently, the complex knowledge of the interlocutor's personality, implicitly during the process of judicial and criminal investigation, the observation and interpretation of nonverbal clues in the scope of communication will favor the development of psychological abilities and skills, as obligatory parts of professional mastery for prosecutors, judges, police officers, and lawyers. Such activities will condition the obtainment of superior performance, through the creative use of the entire set of knowledge, techniques, procedures that define the professional competence of law enforcers in solving a case; at the same time, they will pave the way to the shaping of the magistrate's intimate conviction and to reaching the right judicial solution.

\section{Conclusions}

The efforts of prosecutors and judges, in collaboration with other persons (police officers, lawyers, witnesses, experts, interpreters, etc.), for ascertaining the deeds of the accused, the relations between criminals and their victims, between the two litigating parties, as accurately and objectively as possible, for correctly evaluating the damage incurred by the victim, are regulated by good faith, by ethical values, by the deontological norms of the jurist profession - as internal factors of the magistrate's personality. The conviction and attitudes of magistrates, as dominant traits of character, as vectors of value for their personalities and as intrinsic, axiologically oriented motives, should be durable states of mind, based on superior

94 sciendo Journal of Legal Studies Volume 27 Issue 41/2021 
feelings, oriented by an ideal of life, by their view on the human condition, society, and the world, which guides all professional dealings of magistrates. A case is solved in the process of recreating facts and gathering evidence, the final product of which is the intimate conviction of the magistrate - the subjective support for adopting a judicial decision.

Relations between one magistrate and another, between a magistrate and the accused, between a magistrate and participants in the trial, involve verbal, nonverbal, and paraverbal communication. Throughout the trial, any communicator and any recipient, be they magistrates or litigants, lawyers or witnesses, transmit and receive verbal and extraverbal messages. The more experienced an interlocutor is in communication, the more specialized, skilled, or interested s/he is, the more able s/he will be to decode and interpret the nonverbal expressions of glances, gestures, poise, touching, proximity, stance, or dress. The defendant may express, through his nonverbal conduct, during the judicial investigation, certain manifestations that betray his sincerity; a skilled investigator may identify a duplicitous attitude or a feigned behavior. Sometimes, the reverse situation may also occur: the defendant, endowed with a presence of mind and a rich culture of communication, may interpret certain nonverbal clues as "gaucheries" in the behavior of investigators or magistrates, and change his/her tactic accordingly. Representatives of investigational press, as well as informed and objective observers, are capable of decoding certain nonverbal expressions of magistrates, which betray their good faith or highlight an opposition between what some magistrates do and the fundamental ethical values they have adhered to by oath.

Finally, another practical conclusion can be drawn, namely: the professional training of jurists in general, and magistrates in particular, should include, in terms of undergraduate and postgraduate education, the assimilation and application of knowledge on judicial psychology, sociology of law, logic, ethics and professional deontology, philosophy of law.

\section{Acknowledgments}

The author thanks the anonymous reviewers and editor for their valuable contribution.

\section{Funding}

This research received no specific grant from any funding agency in the public, commercial, or not - for - profit sectors.

\section{Author Contributions}

The entire article was written by Marțian Iovan. 
Iovan, M., (2021)

\section{Disclosure Statement}

The author has not any competing financial, professional, or personal interests from other parties.

\section{References}

1. Argyle, M. (1978). The Psychology of Interpersonal Behavior, Second Edition. Harmondsworth: Penguin.

2. Bogdan, T. (1973). Probleme de psihologie judiciară (Matters of Judicial Psychology). București: Editura Ştiinţifică.

3. Burton, G., Dimbleby, R. (1988). Between Ourselves: An Introduction to Interpersonal Communication. London: Edward Arnold.

4. Butoi, T. (2004). Interogatoriul. Psihologia confruntării în procesul judiciar (Questioning. The Psychology of Confrontation in Judicial Trials). Bucureşti: Editura Pinguin Book.

5. Buş, I. (1997). Psihologie judiciară (Judicial Psychology). Cluj-Napoca: Presa Universitară Clujeană.

6. Chiş, A.A., Moțu, F.I. (2008). Comunicarea profesională în justiţie. Aparența de imparţialitate în contextul comunicării dintre judecători şi avocaţi (Professional communication in the judiciary. The appearance of impartiality in the context of communication between judges and lawyers), in Copoeru, I., Szabo, N. (coord.). (2008), Etică şi cultură profesională (Ethics and Professional Culture). Cluj-Napoca: Casa Cărţii de Ştiință, pp. 167-177.

7. Ciopraga, A. (1996). Criminalistica. Tratat de tactică (Forensic Science. A Treatise of Tactics). Iaşi: Editura Gama.

8. Dworkin, R. (1998). Drepturile la modul serios (Taking Rights Seriously). Chişinău: Editura ARC.

9. Elliott, C., Queen, F. (2002). Criminal Law, Fourth Edition. Great Britain: Pearson Education Limited.

10. Fiske, J. (1990). Introduction to Communication Studies. Londra - New York: Routledge. 11. Gheorghe, F. (1996). Psihologie penitenciară (Penitentiary Psychology). Bucureşti: Editura Oscar Print.

12. Goffman, E. (1969). Behavior in Public Places. Notes on the Social Organization of Gatherings. New York: Free Press.

13. Hart, H.L.A. (1994). The Concept of Law, Second Edition. Oxford: Clarendon University Press.

14. Hegel, G.F.W. (1963). Principiile filosofiei dreptului (Elements of the Philosophy of Right). București: E.A.R., p.256.

15. Hayes, N., Orrell, S. (1997). Introducere în psihologie (Psychology: An Introduction). Bucureşti: Editura All Educational.

16. Iovan, M. (2007). Psihologie judiciară (Judicial Psychology). Arad: "Vasile Goldiş" University Press.

17. Ivan, L. (2009). Competența în comunicarea nonverbală (Competence in Nonverbal Communication). București: TRITONIC Grup Editorial.

18. Malaurie, P. (1997). Antologia gândirii juridice (Anthology of Judicial Thought). Bucureşti: Humanitas.

96 sciendo Journal of Legal Studies Volume 27 Issue 41/2021 
Iovan, M., (2021)

Development of the Magistrate's Intime Conviction in the Context of Non-verbal Communication

19. Mitrofan, N., Zdrenghea, V., Butoi T. (1992). Psihologie judiciară (Judicial Psychology). Bucureşti: Casa de Editură şi Presă "Şansa" S.R.L.

20. O’Sullivan, T., Hartley, J., Saunders, D., Montgomery, M., Fiske, J. (2001). Concepte fundamentale din ştiinţele comunicării şi studiile culturale (Key Concepts in Communication and Cultural Studies). Iaşi: Editura Polirom.

21. Rădulescu, A. (2008). Unele aspecte privind evaluarea comportamentului judecătorilor din perspectivă calitativă (Aspect of evaluation of the behavior of judges from a qualitative perspective), in Copoeru, I., Szabo, N. (coord.). (2008). Etică şi cultură profesională (Ethics and Professional Culture). Cluj-Napoca: Casa Cărţii de Ştiinţă, pp. 256-268.

22. Rusnac, S. (2000). Psihologia dreptului (Psychology of Law). Chişinău: Editura ARC. 